\title{
STUDI KERAPATAN DAN KERAGAMAN JENIS MAKRO ALGAE PADA PERAIRAN DESA JIKUMERASA, KEBUPATEN BURU
}

\section{B. Mornaten}

Pranata Laboratorium Pendidikan F.MIPA Unpatti

\begin{abstract}
ABSTRAK. Studi kerapatan dan keragaman jenis makro algae telah dilaksanakan di perairan Desa Jikumerasa, Kabupaten Buru pada tanggal 19-24 Agustus 2013. Tujuan penelitian ini adalah untuk mengetahui kerapatan dan keragaman jenis makro algae di perairan Desa Jikumerasa, Kabupaten Buru. Pengumpulan data dengan menggunakan metode transek linier kuadrat. Penelitian ini dibagi dalam tiga stasiun, yaitu daerah Lagun (stasiun I), daerah Jikumerasa Besar (stasiun II), dan daerah Jikuerasa Kecil (stasiun III). Dari hasil penelitian ditemukan sebanyak 25 jenis makro algae. Adapun 4 jenis ditemukan di stasiun I, 25 jenis ditemukan di stasiun II, dan 19 jenis ditemukan di stasiun III. Jenis algae yang memiliki nilai kerapatan tertinggi adalah Codium decoticatum dari kelas Chlorophyceae, yaitu sebesar 10,667 $\mathrm{ind} / \mathrm{m}^{2}$. Stasiun II (Jikumerasa Besar) memiliki nilai rata-rata kerapatan jenis makro algae yang tertinggi, yaitu sebesar $5,095 \mathrm{ind} / \mathrm{m}^{2}$. Keragaman jenis makro algae pada perairan Desa Jikumerasa tergolong sedang $(2,5)$.
\end{abstract}

Kata Kunci : Kerapatan, Keragaman, Makro algae, Perairan Desa Jikumerasa, Kabupaten Buru.

\section{Pendahuluan}

Indonesia Makro algae merupakan tumbuhan tingkat rendah yang berukuran makroskopis, dan susunan kerangka tubuhnya tidak dapat dibedakan antara akar, batang dan daun. Dalam dunia tumbuhan, makro algae termasuk dalam regnum Thallophyta (tumbuhan thallus), karena belum mempunyai akar, batang dan daun secara jelas (Anonim, 2008). Menurut Soegiarto (1978), makro algae mempunyai arti penting dari segi ekologi dan segi ekonomi bagi masyarakat pesisir pantai yang mendiami daerah tersebut. Dari segi ekologi makro algae merupakan salah satu komponen penyusun ekosistem laut dan pesisir karena berperan sebagai produsen bagi kelangsungan kehidupan perairan disekitarnya. Dari segi ekonomi makro algae dapat dimanfaatkan sebagai sumber makanan, misalnya genus Gracilaria yang mengandung agarose yang berguna untuk pembuatan ice cream dan selai. Pemanfaatan di bidang farmasi, misalnya genus Laminaria yang mengandung asam alginat yang berguna dalam pembuatan tablet, serta genus Lesonia yang mengandung sodium alginat yang berguna dalam pengisian obat penicicilin. Selain itu ada juga yang dimanfaatkan dalam industri pangan, misalnya genus Chondrus yang mengandung karaginan yang dapat digunakan untuk mengendalikan kandungan air, dan menstabilkan makanan (Winarno, 1990).

Sehubungan dengan arti penting secara ekologi dan ekonomi dari jenis makro algae, maka harus dijaga dan dilindungi untuk meminimalkan kerusakan yang terjadi akibat aktifitas manusia (Mudjono, 1991). Aktifitas manusia yang dapat berdampak langsung terhadap penurunan kergaman jenis makro algae pada perairan Desa Jikumerasa, seperti pembuangan limbah domestik ke pantai dan pengambilan pasir dari pantai.

Sejauh ini data mengenai jenis makro algae terutama tentang kepadatan dan keragamannya pada perairan Jikumerasa masih sedikit diketahui. Beberapa penelitian yang telah dilakukan pada perairan Jikumerasa, tetapi lebih difokuskan pada studi keanekaragaman dan kelimpahan Echinodermata da Lamun. Penelitian mengenai kepadatan dan keragaman jenis makro algae sudah dilakukan tetapi di daerah Ambalau, Kabupaten Buru (Papalia dan Yulianto, 2008).

Berdasarkan potensi yang dimiliki oleh perairan Jikumerasa, dan kemungkinan pengrusakan ekosistem pesisir pantai oleh aktivitas manusia, serta belum ada penelitian sebelumnya tentang kepadatan dan keragaman jenis makro algae di perairan Jikumerasa, maka perlu dilakukan penelitian tentang studi kepadatan dan keragaan jenis makro algae pada perairan Desa Jikumerasa Kabupaten Buru. 


\subsection{Morfologi dan Anatomi Makro algae}

Makro algae merupakan tumbuhan tingkat rendah yang berukuran makroskopis, dan susunan kerangka tubuhnya tidak dapat dibedakan antara akar, batang dan daun. Dalam dunia tumbuhan, makro algae termasuk dalam regnum Thallopyta (tumbuhan thallus), karena belum mempunyai akar, batang dan daun secara jelas (Anonim, 2008). Tubuh makro algae berupa thallus dan memiliki bentuk yang bermacam-macam. Menurut Fortes (1981), thallus terdiri dari holdfast, stipe, dan blade. Holdfast adalah jaringan yang berstruktur keras dan panjang pada makro algae. Fungsi utamanya adalah untuk perlekatan. Stipe adalah jaringan berongga yang merupakan tempat tumbuhnya blade. Fungsi utama untuk mendukung blade. Blade adalah jaringan utama pada makro algae karena terdapat pigmen-pigmen untuk berfotosintesis serta berfungsi sebagai tempat untuk fotosintesis dan (Gambar 1).

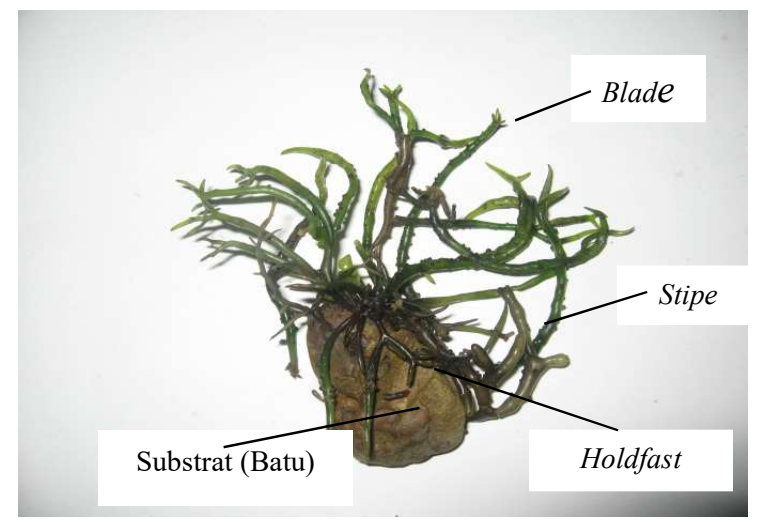

\section{Gambar 1. Morfologi makro algae jenis Gracilaria edulis dengan bagian-bagiannya (Fortes, 1981)}

Makro algae bersifat fotosintetik. Sifat fotosintetik pada makro algae bersifat mutlak karena memiliki tiga macam pigmen fotosintetik yaitu Klorofil, Karotenoid, dan Fikobilin (ketiganya terdapat dalam Plastida). Selain itu, makro algae juga memiliki pigmen lain yaitu Fikosianin (warna biru), Fikosantin (warna coklat), Fikoeritrin (warna merah), dan Xantofil (warna kuning).

Thallus makro algae ada yang berbentuk lembaran, silinder, dan tabung (Gambar 2).
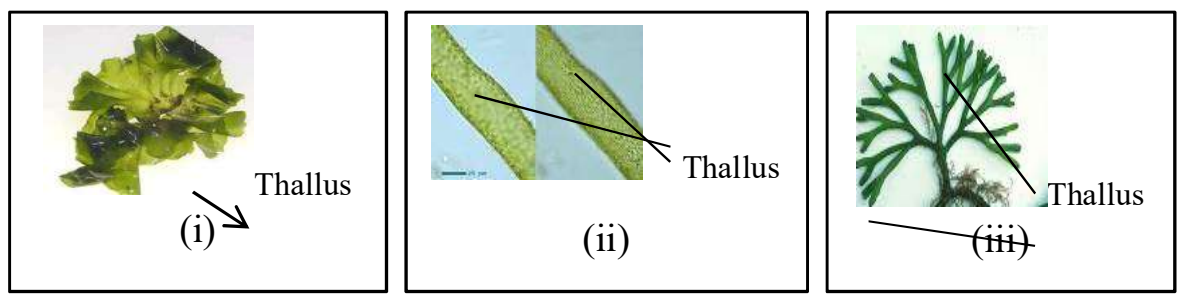

Gambar 2. Bentuk thallus pada jenis makro algae: (i) Bentuk lembaran pada Ulva, (ii) Bentuk tabung pada Vaucheria, (iii) Bentuk silinder pada Codium (Bold dan Wynne, 1978)

\subsection{Habitat dan Penyebaran Makro algae}

Makro alga umumnya hidup di air dan di tempat yang cukup cahaya untuk berfotosintesis. Makro algae berperan sebagai produsen yang menyediakan makanan bagi sebagian besar hewan air (Dawes, 2006). Penyebaran dan pertumbuhan makro algae disuatu perairan sangat dipengaruhi oleh faktor-faktor anatara lain:

1. Substrat 
Jenis substrat merupakan indikator utama bagi kelimpahan makro algae di suatu perairan. Substrat yang digunakan sebagai tempat melekat adalah pasir, batuan, karang, karang mati, pecahan karang, tanaman lain, dan mungkin benda-benda padat yang kebetulan tenggelam di dalam laut (Sadhori, 1991).

2. Cahaya Matahari

Makro algae tumbuh di perairan dengan kedalaman tertentu dimana sinar matahari sampai ke dasar perairan (Sumadiharga, 1997). Intensitas maupun panjang gelombang berpengaruh pada pengendalian penyebaran makro algae, karena makro algae terdiri dari 3 kelas yaitu merah, cokelat, dan hijau, dan ketiganya menyerap spektrum cahaya yang berbeda. Di perairan, algae hijau berada di tempat teratas karena menyerap sinar merah, algae cokelat di tengah, dan terakhir algae merah yang menyerap cahaya hijau terdapat di daerah yang terdalam (Nybakken, 1988).

3. Suhu

Dalam kaitannya dengan pertumbuhan, maka suhu optimal bagi pertumbuhan jenis makro algae berbedabeda tergantung jenis algae dan lintang tempat dimana algae itu berada. Menurut Atmadja (2007), jenis makro algae yang berada di daerah kutub dapat tumbuh dengan baik pada suhu $0-10^{\circ} \mathrm{C}$, sedangkan jenis makro algae yang hidup di daerah iklim sedang yang agak dingin dapat hidup dapat tumbuh dengan baik pada suhu $10-15^{0} \mathrm{C}$. Jenis makro algae yang hidup di daerah iklim sedang yang agak hangat dapat tumbuh dengan baik pada suhu $10-20^{\circ} \mathrm{C}$, sedangkan jenis makro algae yang hidup di daerah tropis dapat tumbuh dengan baik pada suhu $15-30^{\circ} \mathrm{C}$ (Luning, 1990).

4. Salinitas

Salinitas perairan yang ideal bagi kehidupan makro algae adalah 28-34 permil, dimana salinitas optimumnya adalah 32 permil (Ambas, 2006).

5. Nutrien

Penyerapan nutrisi dilakukan melalui seluruh bagian tubuhnya (Indriani, 1997). Phosphor dan nitrogen secara normal konsentrasinya rendah di dalam air laut, sehingga sering menjadi faktor pembatas untuk pertumbuhan makro algae. Nitrogen diserap oleh makro algae dalam bentuk nitrat dan ammonium (Junaidi, 2004).

6. Derajat Keasaman $(\mathrm{pH})$

Merupakan salah satu faktor yang mempengaruhi pertumbuhan makro algae, dimana nilai $\mathrm{pH}$ sangat menentukan molekul karbon yang digunakan makro algae untuk fotosintesis (Sadhori, 1991).

7. Gerakan Air

Gerakan air mengalir (arus) yang baik untuk pertumbuhan makro algae yaitu antara 20-40 cm/detik. Sedangkan gerakan air yang bergelombang (ombak) harus tidak lebih dari $30 \mathrm{~cm}$. Bila arus air lebih cepat maupun ombak lebih tinggi, dapat menyebabkan makro algae robek, rusak dan terlepas dari substrat. Selain itu, penyerapan zat hara akan terhambat karena belum sempat diserap sudah dibawa kembali oleh air laut (Rais, 2008).

8. Organisme Pemakan Makro algae

Organisme pemakan makro algae diantaranya adalah hewan laut dari kelas Echinodea, yang hidup di atas batu karang atau dalam lumpur pada pantai (Rais, 2008) (Gambar 3).

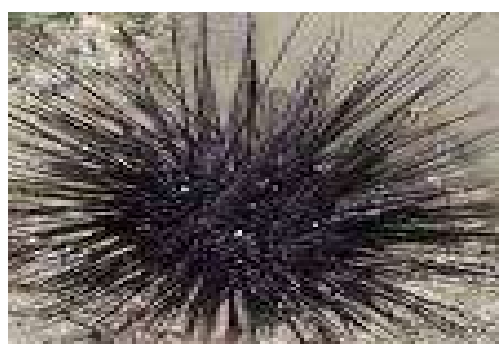

Gambar 3. Organisme pemakan makro algae dari kelas Echinode 
1.3. Klasifikasi Makro algae

Webber dan Thurman (1985), menggolongkan makro algae menjadi 3 kelas yaitu : Rhodophyceae, Chlorophyceae, dan Phaeophyceae. Sistem klasifikasi salah satu spesies dari makro algae (Anonim, 2005), sebagai berikut:

$\begin{array}{ll}\text { Kingdom } & \text { : Plantae } \\ \text { Divisi } & \text { : Thallophyta } \\ \text { Sub Divisi } & \text { : Algae } \\ \text { Kelas } & \text { : Chlorophyceae } \\ \text { Ordo } & \text { : Halimedales } \\ \text { Family } & \text { : Halimedaceae } \\ \text { Genus } & : \text { Halimeda } \\ \text { Spesies } & : \text { Halimeda opuntia }\end{array}$

1. Kelas Chlorophyceae (Algae hijau)

Kelas Chlorophyceae atau algae hijau merupakan kelompok terbesar dari algae yang terdiri dari lebih kurang 429 marga dan 6600 jenis.

Menurut Gupta (1981) dalam Dewi (2006) Chlorophyceae dikenal dengan ciri-ciri yang sangat khas yaitu: (a) Mempunyai pigmen yang terdapat dalam kloroplas yang didominasi oleh klorofil a dan b sehingga menyebabkan algae ini berwarna hijau (b) Produk asimilasi berupa pati.(c) Dinding sel terdiri atas selulosa. Reproduksi algae hijau dilakukan dengan tiga cara, yaitu cara vegetatif, aseksual, dan seksual.

Sebaran algae hijau terdapat terutama di daerah litoral tepatnya pada kedalaman 10 meter (Bell dan Hemsley, 2004). Di Indonesia tercatat sedikitnya 12 genus algae hijau yang banyak dijumpai di perairan pantai, beberapa marga-marga algae itu adalah sebagai berikut: Caulerpa, Ulva, Valonia, Dictyosphaera, Halimeda, Chaetomorpha, Codium, Udotea, Tydemania, Bernetella, Burgenesia, dan Neomeris (Romimohtarto, 2001).

2. Kelas Phaeophyceae (Algae coklat)

Ciri khas pada algae coklat sebagai berikut: (a) Algae coklat mempunyai Fikosantin dalam jumlah banyak sehingga menyebabkan warna coklat sampai hijau kecoklatan. $\quad$ (b) Cadangan makanan berupa lemak.

(c) Dinding sel menghasilkan asam alginate (Atmadja, 1996).

Smith (1955), membagi kelas algae coklat menjadi 3 kelas sebagai berikut: (a) Kelas Isogeneratae, merupakan kelas yang daur hidupnya menunjukkan pergantian yang isomorf. Contohnya bangsa Ectocarpales, dan Dictyotales. (b) Kelas Heterogeneratae, merupakan kelas yang daur hidupnya menunjukkan pergantian yang heteromorf. Contohnya bangsa Laminariales, dan Desmarestiales. (c) Kelas Cyclosporae, merupakan kelas yang tidak menunjukkan adanya pergantian keturunan, hanya mempunyai keturunan yang diploid saja. Contohnya bangsa Fucales. Algae coklat banyak ditemukan pada air laut. Yang hidup di air laut terutama terdapat di daerah yang beriklim dingin dan tidak banyak yang terdapat di daerah tropik. Menurut Romimohtarto (2001), di Indonesia terdapat delapan marga algae coklat yang ditemukan yaitu : Cystoseira, Dictyopteris, Dictyota, Hormophysa, Hydroclathrus, Padina, Sargasum, dan Turbinaria

3. Kelas Rhodophyceae (Algae merah)

Ciri khas dari algae merah yaitu: (a) Memilki pigmen fikoeritrin yang dominan sehingga menyebabkan warna merah (b) Cadangan makanan berupa tepung floridae (c) Dinding sel mengandung selulosa dan polisakarida. Reproduksi secara seksual dan aseksual.

Sebaran algae merah sangat luas, tetapi banyak terdapat di perairan beriklim sedang. Beberapa jenis algae ini terdapat di daerah sebaran pasang surut, tetapi pertumbuhan yang subur terdapat di daerah pasang surut.

Di Indonesia tercatat 17 marga algae merah yang terdiri dari 34 jenis. Marga algae tersebut diantaranya yaitu : Acanthophora, Actinotrichia, Amansia, Amphiroa, Chondrcoccu, Corallina, Euchema, Galaxaura, Gelidiella, Gigartina, Gracilaria, Halymenia, Hypnea, Laurencia, Rhodimenia, Titanopyra, dan Porpyra (Romimohtarto, 2001).

1.4. Manfaat Makro algae

Makro algae memiliki nilai ekonomis yang sangat penting karena dapat dimanfaatkan untuk memenuhi kebutuhan hidup manusia. Kandungan yang terdapat dalam makro algae adalah alginat, agarose dan karaginan (Sumadiharga, 1997).

Alginat merupakan hidrokoloid yang diekstraksi dari Phaeophyceae (algae coklat). Alginat menjadi sangat penting karena penggunaannya yang cukup luas dalam industri, antara lain sebagai pemelihara bentuk jaringan 
pada makanan yang dibekukan, pengerasan dalam industri roti berlapis gula, pensuspensi dalam sirop, serta penambah busa pada industri bir. Contoh Algae pennghasil alginat yaitu berasal dari genus Laminaria, Lesonia, Ascophyllum, Sargassum, dan Turbinaria (Sumadiharga, 1997).

Agar-agar merupakan hidrokoloid algae yang berupa gel. Senyawa ini dihasilkan dari proses ekstraksi algae merah. Sebagian besar agar-agar digunakan oleh industri makanan dalam bentuk jelly, ice cream, makanan kaleng (daging dan ikan), roti, permen, manisan, dan selai. Contoh algae penghasil agar-agar yaitu dari genus Gracilaria, Gelidium, Pterocladia, Acanthopeltis, dan Ceramium (Winarno, 1990).

Karaginan adalah senyawa hidrokoloid yang diekstraksi dari algae merah. Karaginan tidak dapat dimakan oleh manusia dan tidak memilki nutrisi yang diperlukan oleh tubuh. Oleh karena itu, karaginan hanya digunakan dalam industri pangan karena fungsi karakteristiknya yang dapat digunakan untuk mengendalikan kandungan air, mengendalikan tekstur, dan menstabilkan makanan (Winarno, 1990). Contoh algae penghasil karaginan yaitu dari genus Euchema, Chondrus, Hypnea, dan Gigartina (Thana dan Tandipayuk, 1993).

\subsection{Parameter Ekologi}

Menurut Soegianto (1994), kepadatan menunjukan jumlah individu spesies dalam satu luasan tertentu. Fenomena alam seperti pasang surut, kondisi fisik dan kimia perairan dan kondisi substrat sangat mempengaruhi keberadaan dan kepadatan spesies. Keragaman spesies penting dari segi ekologi karena dapat digunakan untuk menunjukan struktur komunitas pada suatu wilayah perairan.

Frekuensi suatu jenis menunjukan jumlah individu suatu spesies pada petak pengamatan per luasan area tertentu pada suatu daerah. Spesies yang memiliki kepadatan yang tinggi maka nilai frekuensi kehadirannya juga tinggi. Hal ini disebabkan karena spesies-spesies tersebut memiliki penyebaran yang sangat luas dan mempunyai toleransi yang tinggi terhadap perubahan lingkungan. Dominansi menunjukkan jumlah total individu terbanyak dari tiap spesies dalam suatu komunitas. Menurut Soegianto (1994), spesies yang dominan di suatu komunitas perairan mempunyai presentasi jumlah individu yang besar bila dibandingkan dengan spesies yang jarang ditemukan. Hal ini disebabkan karena tidak semua tempat di wilayah perairan merupakan habitat yang layak bagi spesies tersebut karena dipengaruhi olah faktor-faktor lingkungan seperti jenis dan jumlah makanan, predasi dan kompetisi.

Bila suatu daerah cenderung didominasi oleh jenis spesies tertentu saja, maka daerah tersebut dapat dikatakan memiliki keragaman jenis yang rendah. Keragaman jenis disebabkan karena terdapat banyaknya jumlah spesies yang beda dalam suatu komunitas. Banyaknya jumlah spesies yang beda tersebut disebabkan karena terdapatnya variasi. Keragaman jenis terdiri dari dua komponen yaitu:

a. Jumlah jenis dalam komunitas yang sering disebut kekayaan jenis.

b. Kesamaan jenis yang menunjukkan kelimpahan spesies tersebut (Ludwiq and Reynolds, 1988).

\section{Metode}

Analisa Kepadatan, Frekuensi kehadiran, Indeks keragaman jenis 1963), dan Indeks dominansi. (Shannon dan Wiener),

1. Kepadatan

Untuk menghitung kepadatan adalah jumlah individu dan luas area pengambilan sampel. Kepadatan adalah jumlah individu per satuan luas area. Rumus untuk menghitung kepadatan individu adalah sebagai berikut:

$$
\text { Di }=\frac{\text { ni }}{\mathbf{A}}
$$

Dimana: $\mathrm{Di}=$ Kepadatan individu spesies ke-i $\left(\mathrm{ind} / \mathrm{m}^{2}\right)$

$\mathrm{ni}=$ Jumlah individu spesies ke-i

$\mathrm{A}=$ Luas area pengambilan sampel

2. Frekuensi kehadiran

Untuk menghitung frekuensi kehadiran adalah jumlah petak pengamatan ditemukannya spesies dan jumlah seluruh petak pengamatan yang dibuat. Frekuensi kehadiran menunjukan banyaknya petak pengamatan dimana suatu spesies ditemukan dalam luasan tertentu yang dinyatakan dengan rumus menurut sebagai berikut:

$$
\text { Fi }=\frac{\mathrm{Ji}}{\mathrm{K}} \times \mathbf{1 0 0 \%}
$$


Dimana: $\mathrm{Fi}=$ Frekuensi untuk spesies ke-i

$\mathrm{Ji}=$ Jumlah petak pengamatan terdapat spesies ke-i

$\mathrm{K}=$ Jumlah seluruh petak pengamatan yang dibuat

3. Indeks keragaman jenis

Untuk menghitung indeks keragaman jenis adalah jumlah individu spesies ke-i dan jumlah total spesies. Indeks keragaman jenis dapat dihitung menurut indeks diversitas Shannon dan Wiener (1963) dengan rumus :

$$
\mathbf{H}^{\prime}=-(\Sigma \text { pi ln pi) }
$$

dimana : $\mathrm{H}^{\prime}=$ Indeks keragaman jenis

$\mathrm{pi}=$ Probalitas penting untuk setiap spesies $\mathrm{ke}-\mathrm{i}=\mathrm{ni} / \mathrm{N}$

ni $=$ Jumlah individu spesies ke-i

$\mathrm{N}=$ Jumlah total spesies

\section{Indeks Dominansi}

Untuk menghitung indeks dominansi adalah jumlah individu spesies ke-i dan jumlah total spesies. Dominansi menunjukan spesies tertentu yang paling banyak terdapat dalam komunitas.

Dominansi spesies ditentukan berdasarkan indeks Simpson sebagai berikut :

$$
\mathbf{D}=\sum(\mathbf{p i})^{\mathbf{2}}
$$

Dimana : $\mathrm{D}=$ Nilai indeks dominan spesies

$\mathrm{Pi}=$ Perbandingan jumlah individu spesies ke-i (ni) terhadap jumlah total spesies $(\mathrm{N})=\mathrm{ni} / \mathrm{N}$

Jika $\mathrm{D}=1$ maka dominansi tinggi (ada spesies yang dominan)

Jika $\mathrm{D}=0$ maka dominansi rendah (Tidak ada spesies yang dominan).

\subsection{Peralatan dan Bahan}

Bahan - bahan yang digunakan adalah jenis makro algae dari Desa Jikumerasa Kabupaten Buru , formalin $4 \%$, tissue. Peralatan yang digunakan pada penelitian ini yaitu : meter roll, tali nilon, petak pengamatan (kuadran yg terbuat dari pipa paralon dengan ukuran 1 x 1 meter), plastik sampel (plastik ukuran $1 \mathrm{~kg}$ ), pelampung, kamera underwater, spin masker, alat tulis menulis (spidol, pensil, dan kertas underwater), dan buku identifikasi jenis makro algae (Cordero, 1980).

\subsection{Persiapan Sampel}

Sebelum melakukan penelitian, dilakukan survey awal dan komunikasi dengan masyarakat mengenai tempat atau lokasi penelitian. Lokasi penelitian yang dipilih adalah di daerah Lagun (Stasiun I) dengan luas pantai sebesar $18.665 \mathrm{~m}^{2}$, daerah Jikumerasa Besar (Stasiun II) dengan luas pantai sebesar $9.650 \mathrm{~m}^{2}$, dan daerah Jikumerasa Kecil (Stasiun III) dengan luas pantai sebesar $7.220 \mathrm{~m}^{2}$. Alat-alat yang digunakan dipersiapkan dan diperiksa kelengkapannya.

\subsubsection{Tahap Pelaksanaan}

Langkah-langkah kerja pada penelitian ini yaitu :

a. Pada setiap stasiun dibuat 3 buah transek yang diletakan tegak lurus garis pantai yang dimulai dari titik pasang tertinggi ke arah laut dengan panjang transek $100 \mathrm{~m}$.

b. Selanjutnya pada setiap interval $10 \mathrm{~m}$ dari pasang tertinggi pada masing-masing transek diletakan petak pengamatan dengan ukuran 1 x $1 \mathrm{~m}$ sebanyak 10 buah (Gambar 8).

c. Sampel jenis makro algae yang terdapat dalam petak pengamatan diidentifikasi spesiesnya dan dihitung jumlahnya. 
d. Selanjutnya data jumlah spesies dan jumlah individu setiap spesies digunakan untuk menghitung Kerapatan, Frekuensi kehadiran, Indeks keragaman jenis (Shannon dan Wiener, 1963), dan Indeks dominansi.

e. Jenis makro algae yang tidak teridentifikasi di lokasi penelitian, dimasukan lagi ke dalam plastik sampel yang sudah di beri kode sesuai dengan di transek dan di petak pengamatan keberapakah jenis makro algae itu di temukan dan selanjutnya jenis makro algae diawetkan dengan formalin $4 \%$.

f. Setelah itu jenis makro algae di bawah ke Laboratorium Biologi untuk diidentifikasi dengan menggunakan buku identifikasi makro algae menurut Cordero (1980).Pengambilan sampel daun lamun di perairan Desa Suli. Pembuatan teh daun lamun (Enhalus Tea) dan pengujian sifat hedonik dan sifat sensori dilaksanakan di Laboratorium Biologi Dasar FKIP Universitas Pattimura Ambon. Waktu pengambilan sampel pada tanggal 13 Juni 2019 dan pembuatan Enhalus Tea serta pengujian sifat hedonik dan sensorik berlangsung pada tanggal 14-17 Juni 2019. Alat dan bahan yang digunakan dalam penelitian ini adalah penampan, pisau, timbangan analitik, saringan, hot plate, gelas ukur, gelas kimia, blender, oven, kipas angin, toples, daun lamun (Enhalus acoroides) dan air. Pembuatan Enhalus Tea diadaptasi dari pembuatan teh daun lamun (Harfelein dkk., 2018).

\section{Hasil Penelitian}

\subsection{Kepadatan, dan Frekuensi Kehadiran Jenis Makro algae di Perairan Desa Jikumerasa, Kabupaten Buru}

Dari hasil penelitian ditemukan 25 jenis makro algae di perairan desa Jikumerasa Kabupaten Buru. Adapun 4 jenis ditemukan di stasiun I, 25 jenis ditemukan di stasiun II, dan 19 jenis ditemukan di stasiun III. Dengan perbendingan algae hijau : algae coklat : algae merah adalah $12: 7: 6$, dimana algae hijau mempunyai jenis yang banyak, kemudian algae coklat, dan algae merah yang mempunyai jenis yang sedikit. Nilai rata-rata kepadatan dan frekuensi kehadiran jenis makro algae di perairan Desa Jikumerasa pada masing-masing stasiun dapat dilihat pada tabel 1, 2, 3, dan gambar 9 .

Tabel 1. Nilai Rata-rata Kepadatan, dan Frekuensi Kehadiran Jenis Makro algae di Stasiun I (Lagun) Perairan Desa Jikumerasa, Kabupaten Buru tahun 2013.

\begin{tabular}{|c|c|l|c|c|}
\hline \multirow{2}{*}{ Stasiun Penelitian } & \multirow{2}{*}{ Kelas } & Jenis & $\begin{array}{c}\text { K } \\
\left(\mathbf{I n d} / \mathbf{m}^{\mathbf{2}}\right)\end{array}$ & $\begin{array}{c}\text { F } \\
(\mathbf{\%})\end{array}$ \\
\hline \multirow{2}{*}{$\begin{array}{c}\text { I } \\
\text { (Lagun) }\end{array}$} & \multirow{3}{*}{ Chlorophyceae } & Caulerpa racemosa & 1,600 & 33,3 \\
\cline { 3 - 5 } & & Halimeda opuntia & 0,867 & 13,3 \\
\cline { 3 - 5 } & & Halimeda makroloba & 0,533 & 6,7 \\
\cline { 3 - 5 } & Phaeophyceae & Padina crassa & 1,167 & 23,2 \\
\hline \multicolumn{2}{|c|}{ Rata-rata (x) } & $\mathbf{1 , 0 4 1}$ & $\mathbf{1 9 , 1 2}$ \\
\hline
\end{tabular}

Tabel 2. Nilai Rata-rata Kepadatan, dan Frekuensi Kehadiran Jenis Makro algae di Stasiun II (Jikumerasa Besar) Perairan Desa Jikumerasa, Kabupaten Buru tahun 2013.

\begin{tabular}{|c|c|c|c|c|}
\hline Stasiun Penelitian & Kelas & Jenis & $\begin{array}{c}\text { K } \\
\left(\mathbf{I n d} / \mathbf{m}^{2}\right)\end{array}$ & $\begin{array}{c}F \\
(\%)\end{array}$ \\
\hline & \multirow{8}{*}{ Chlorophyceae } & Codium decorticatum & 10,667 & 76,7 \\
\hline & & Codium geppiorum & 8,900 & 60 \\
\hline & & Neumeris annulata & 8,033 & 56,7 \\
\hline & & Caulerpa racemosa & 7,833 & 53,3 \\
\hline & & Caulerpa sertularoides & 7,533 & 53,3 \\
\hline & & Halimeda opuntia & 5,633 & 50 \\
\hline & & Halimeda discoidea & 5,333 & 40 \\
\hline & & Halimeda makroloba & 3,700 & 36,7 \\
\hline
\end{tabular}




\begin{tabular}{|c|c|c|c|c|}
\hline \multirow{17}{*}{$\begin{array}{c}\text { II } \\
\text { (Jikumerasa Besar) }\end{array}$} & & Valonia macrophysa & 3,267 & 33,3 \\
\hline & & Bodlea coacta & 2,733 & 23,3 \\
\hline & & Ulva reticulate & 2,233 & 10 \\
\hline & & Ulva fasciata & 1,967 & 6,7 \\
\hline & \multirow{7}{*}{ Phaeophyceae } & Hydroclathratus clatratus & 8,967 & 60 \\
\hline & & Padina crassa & 4,700 & 46,7 \\
\hline & & Padina australis & 4,500 & 40 \\
\hline & & Dictyopteris acrostichoides & 4,033 & 33,3 \\
\hline & & Sargassum cincatum & 2,667 & 33,3 \\
\hline & & Turbinaria conoides & 2,300 & 23,3 \\
\hline & & Turbinaria ornate & 1,367 & 10 \\
\hline & \multirow{6}{*}{ Rhodophyceae } & Jania rubens & 8,200 & 40 \\
\hline & & Liagora caenomyce & 6,033 & 33,3 \\
\hline & & Galaxaura subfruticolosa & 5,600 & 26,7 \\
\hline & & Gracilaria lichenoides & 4,500 & 16,7 \\
\hline & & Acanthophora specivera & 3,967 & 13,3 \\
\hline & & Gracilaria crassa & 2,700 & 13,3 \\
\hline \multicolumn{3}{|c|}{ Rata-rata (x) } & 5,094 & 35,59 \\
\hline
\end{tabular}

Tabel 3. Nilai Rata-rata Kepadatan, dan Frekuensi Kehadiran Jenis Makro algae di Stasiun III (Jikumerasa Kecil) Perairan Desa Jikumerasa, Kabupaten Buru tahun 2013.

\begin{tabular}{|c|c|c|c|c|}
\hline Stasiun Penelitian & Kelas & Jenis & $\begin{array}{c}\mathrm{K} \\
\left(\mathrm{Ind} / \mathbf{m}^{2}\right)\end{array}$ & $\begin{array}{c}F \\
(\%)\end{array}$ \\
\hline \multirow{19}{*}{$\begin{array}{c}\text { III } \\
\text { (Jikumerasa Kecil) }\end{array}$} & \multirow{9}{*}{ Chlorophyceae } & Neumeris annulata & 7,800 & 63,3 \\
\hline & & Caulerpa sertularoides & 4,233 & 60 \\
\hline & & Caulerpa racemosa & 3,967 & 40 \\
\hline & & Halimeda opuntia & 2,933 & 26,7 \\
\hline & & Halimeda discoidea & 2,400 & 26,7 \\
\hline & & Codium geppiorum & 2,033 & 26,7 \\
\hline & & Valonia macrophysa & 1,767 & 20 \\
\hline & & Ulva reticulate & 0,600 & 13,3 \\
\hline & & Bodlea coacta & 0,333 & 6,7 \\
\hline & \multirow{5}{*}{ Phaeophyceae } & Hydroclathratus clatratus & 7,033 & 53,3 \\
\hline & & Padina crassa & 3,967 & 46,7 \\
\hline & & Padina australis & 2,833 & 30 \\
\hline & & Dictyopteris acrostichoides & 1,433 & 20 \\
\hline & & Turninaria ornate & 0,533 & 13,3 \\
\hline & \multirow{5}{*}{ Rhodophyceae } & Galaxaura subfruticolosa & 4,500 & 50 \\
\hline & & Liagora caenomyce & 4,200 & 40 \\
\hline & & Acanthophora specivera & 3,267 & 33,3 \\
\hline & & Gracilaria crassa & 1,567 & 26,7 \\
\hline & & Gracilaria lechenoides & 0,500 & 20 \\
\hline \multicolumn{3}{|c|}{ Rata-rata (x) } & 2,942 & 32,45 \\
\hline
\end{tabular}

Dari hasil penelitian terlihat bahwa, jenis algae hijau memiliki jumlah yang banyak bila dibandingkan dengan jenis algae coklat dan jenis algae merah karena jenis algae hijau bersifat subbarial, artinya banyak yang 
hidup dipermukaan perairan sehingga proses penyerapan cahaya matahari dapat berlangsung dengan baik akibatnya jumlah spesies yang ditemukan lebih banyak. Hal ini didukung oleh pendapat Aslan (1998), yang menyatakan bahwa pada umumnya penyebaran jenis algae hijau banyak di daerah permukaan perairan yang terdapat sinar matahari yang cukup untuk dapat berlangsungnya proses fotosistesis. Daerah ini merupakan tempat yang cocok bagi kehidupan jenis algae hijau karena terdiri atas batuan

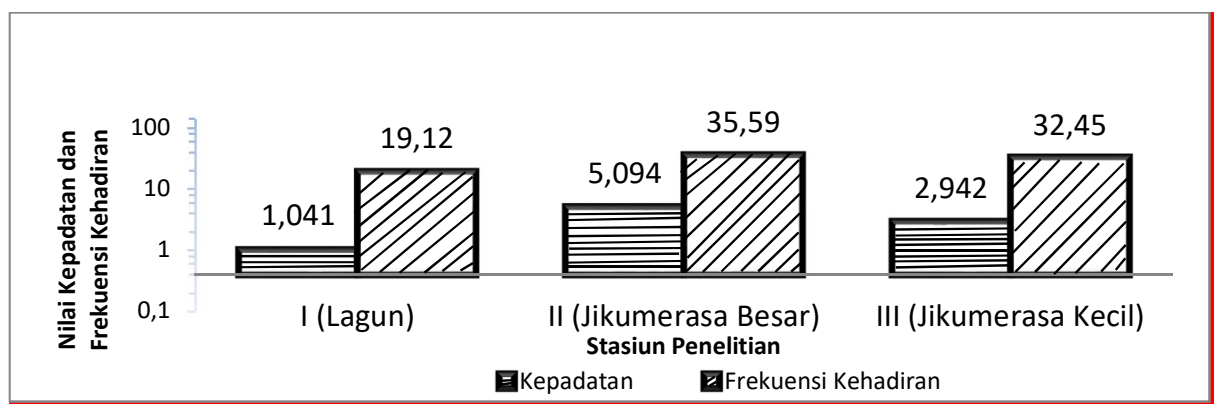

Gambar 4. Histogram nilai rata-rata kepadatan dan frekuensi kehadiran jenis makro algae di ketiga stasiun penelitian di perairan Desa Jikumerasa Kabupaten Buru.

Stasiun penelitian yang mempunyai nilai rata-rata kepadatan dan frekuensi kehadiran jenis makro algae tertinggi adalah stasiun II (Jikumerasa Besar) yaitu sebesar 5,094 ind $/ \mathrm{m}^{2}$ dan 35,59\%, diikuti oleh stasiun III (Jikumerasa Kecil) yaitu sebesar 2,942 ind $/ \mathrm{m}^{2}$ dan 32,45 \%, dan stasiun I (Lagun) yang mempunyai nilai kepadatan dan frekuensi kehadiran jenis makro algae yang terendah yaitu sebesar 1,041 ind $/ \mathrm{m}^{2}$ dan 19,12\%.

Tingginya nilai rata-rata kepadatan dan frekuensi kehadiran jenis makro algae di stasiun II dikarenakan substrat pendukung pada stasiun penelitian ini berupa substrat keras seperti, karang mati, pecahan karang, batuan, dan pasir kasar, sehingga cocok untuk pertumbuhan jenis makro algae, akibatnya banyak jumlah jenis makro algae yang ditemukan pada stasiun ini. Hal ini didukung oleh Sadhori (1991), yang menyatakan substrat yang cocok sebagai habitat jenis makro algae adalah pasir, batuan, karang mati, tanaman lain, dan mungkin benda-benda padat yang kebetulan tenggelam di dalam laut.

Rendahnya nilai rata-rata kepadatan dan frekuensi kehadiran jenis makro algae di stasiun I dikarenakan substrat pendukung lebih didominasi oleh pasir dan lumpur sehingga tidak cocok sebagai habitat sebagian besar jenis makro algae, akibatnya jumlah jenis makro algae yang didapatkan sangat sedikit. Ada beberapa genus makro algae yang dapat bertahan hidup pada substrat yang berlumpur karena mempunyai holdfast berupa kumparan massa akar serabut.

Menurut Soegianto (1994), kepadatan ditentukan oleh banyaknya jumlah jenis yang didapatkan. Semakin banyak jumlah jenis, maka semakin tinggi nilai kepadatannya, sebaliknya semakin sedikit jumlah jenis, maka semakin rendah nilai kepadatannya. Jenis dengan nilai kepadatan tertinggi menunjukan bahwa jenis tersebut mempunyai kehadiran dalam jumlah yang banyak. Sebaliknya, jenis dengan nilai kepadatan yang rendah menunjukan bahwa jenis tersebut mempunyai kehadiran yang relatif sedikit.

Tingginya nilai kepadatan jenis Codium decorticatum di stasiun II karena banyak ditemukan menempel pada karang mati, dan pecahan karang. Jenis algae ini juga banyak yang hidupnya berasosiasi dengan lamun. Hal ini didukung oleh Indriani (1997), menyatakan bahwa jenis Codium decorticatum akan tumbuh baik pada habitat yang bersubstrat keras, dan dapat berasosiasi dengan lamun.

Rendahnya nilai kepadatan jenis Turbinaria ornata di stasiun II karena jenis algae ini hidup menempel pada benda-benda padat yang tenggelam. Dalam penelitian ini, jenis Turbinaria ornata ditemukan saat peneliti menemukan benda-benda padat yang tenggelam pada petak pengamatan. Jenis Turbinaria ornata biasanya tumbuh baik pada substrat keras di rataan terumbu (Rais, 2008).

Tingginya nilai kepadatan jenis Neumeris annulata ditentukan oleh substrat yang sesuai di stasiun III yaitu pecahan karang, karang mati, dan batuan. Sadhori (1991), menyatakan bahwa habitat jenis Neumeris annulata yaitu pada koloni karang mati, pecahan karang, dan batuan.

Rendahnya nilai kepadatan jenis Bodlea coacta di stasiun III karena jenis algae ini ditemukan tersembunyi disela-sela dalam koloni karang mati. Dalam penelitian ini, jenis Bodlea coacta ditemukan saat peneliti 
menghancurkan karang mati yang terdapat di dalam petak pengamatan. Jenis Bodlea coacta biasanya hidup pada habitat yang bersubstrat keras (Rais, 2008).

Tingginya nilai kepadatan jenis Caulerpa racemosa di stasiun I karena jenis algae ini banyak yang hidup menempel pada karang mati dan dapat bertahan hidup pada lumpur. Hal ini didukung oleh Romimohtarto (2001), menyatakan bahwa pertumbuhan jenis Caulerpa racemosa banyak pada karang mati, pecahan karang, dan lumpur. Holdfast berupa kumpulan massa akar serabut, sehingga mampu menempel pada substrat keras dan lumpur.

Rendahnya nilai kepadatan jenis Halimeda makroloba di stasion I karena jenis algae ini tidak mampu bertahan hidup di substrat yang didominasi oleh lumpur. Hal ini didukung oleh Dewi (2006), menyatakan bahwa jenis Halimeda makroloba akan tumbuh baik pada substrat yang didominasi oleh karang karena jenis algae ini mempunyai holdfast berupa kumpulan masa akar tunggang yang hanya mampu menempel substrat yang keras saja.

\subsection{Keragaman dan Dominansi}

Data hasil penelitian yang diperoleh berupa nilai keragaman dan dominansi jenis makro algae di perairan Desa Jikumerasa Kabupaten Buru dapat dilihat pada tabel 4 dan gambar 10.

Tabel 4. Nilai keragaman, dominansi dan jumlah jenis makro algae di perairan Desa Jikumerasa, Kabupaten Buru tahun 2013.

\begin{tabular}{|l|c|c|c|}
\hline \multirow{2}{*}{\multicolumn{1}{|c|}{ Parameter }} & \multicolumn{3}{c|}{ Stasiun Penelitian } \\
\cline { 2 - 4 } & Stasiun I & Stasiun II & Stasiun III \\
\hline Keragaman (H') & 1,3 & 2,8 & 1,9 \\
\hline Dominansi (D) & 0,3 & 0,1 & 0,1 \\
\hline Jumlah jenis & 4 & 25 & 19 \\
\hline
\end{tabular}

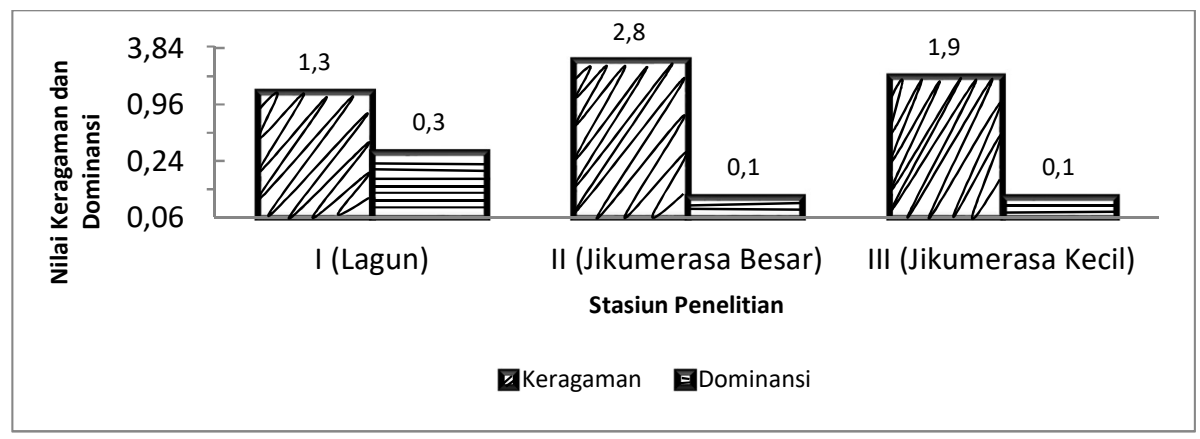

Gambar 5. Histogram nilai keragaman dan dominansi jenis makro algae di ketiga stasiun penelitian di perairan Desa Jikumerasa Kabupaten Buru.

Dari tabel 4 diketahui bahwa nilai keragaman jenis makro algae di stasiun II lebih tinggi yaitu sebesar 2,8, stasiun III sebesar 1,9, dan stasiun I sebesar 1,3. Berdasarkan indeks keragaman jenis untuk makro algae yang dihitung dengan kriteria menurut Brower dan Zar (1990), jika nilai keragaman lebih dari 3,3 maka keragaman jenis tinggi, jika nilai keragaman lebih dari 2,3 dan kurang dari 3,3 maka keragaman jenis sedang, dan jika nilai keragaman kurang dari 2,3 maka keragaman jenis rendah.

Keragaman jenis makro algae di stasiun I bernilai kurang dari 2,3 yang mengindikasikan bahwa tingkat keragaman jenis makro algae di stasiun I adalah rendah, keragaman jenis makro algae di stasiun II bernilai lebih dari 2,3 yang mengindikasikan bahwa tingkat keragaman jenis makro algae di satsiun II adalah sedang, dan keragaman jenis makro algae di stasiun III bernilai kurang dari 2,3 yang mengindikasikan bahwa tingkat keragaman jenis makro algae di stasiun III adalah rendah.

Perbedaan nilai keragaman jenis makro algae pada setiap stasiun karena adanya perbedaan kondisi lingkungan, dan adanya pengaruh aktifitas manusia. Keragaman jenis cenderung akan tinggi jika faktor-faktor lingkungan berada dalam kisaran toleransi bagi kehidupan suatu jenis (Odum, 1998). 
Stasiun II mempunyai kondisi lingkungan yang baik, dimana substrat pendukung terdiri atas karang mati, pecahan karang, batuan, pasir, dan ekosistem lamun, sehingga sangat cocok untuk habitat jenis makro algae. Selain itu transparansi juga baik sehingga penetrasi cahaya dapat menembus sampai ke dasar perairan, serta tidak adanya pengaruh aktifitas manusia karena belum adanya pemukiman warga.

Stasiun III mempunyai substrat berupa karang mati, pacahan karang, batuan, dan pasir, tetapi pada stasiun ini sedikit terganggu habitat jenis makro algae karena adannya pengambilan pasir secara ilegal oleh masyarakat sekitar, dan ditambah lagi dengan kurang adanya kesadaran masyarakat sekitar yang cenderung membuang sampah ke pantai.

Stasiun I mempunyai substrat didominasi oleh lumpur dan pasir, serta airnya yang telah bercampur dengan air tawar dari sungai sekitar sehingga menyebabkan salinitasnya rendah. Banyak terdapat pemukiman warga, dan ditambah lagi dengan pencemaran yang disebabkan oleh pembuangan limbah domestik secara berlebihan.

Tingkat keragaman jenis makro algae yang tergolong sedang dan rendah di ketiga stasiun penelitian juga dapat disebabkan oleh salinitas, $\mathrm{pH}$, dan suhu perairan. Menurut Nybakken (1988), nilai keragaman yang tinggi menunjukkan bahwa faktor lingkungan relatif stabil dan mampu mendukung kehidupan organismenya. Jika dibandingkan dengan hasil penelitian yang dilakukan oleh beberapa peneliti di Indonesia, ditemukan bahwa keragaman jenis makro algae di stasiun I dan stasiun III lebih rendah, sebaliknya keragaman jenis makro algae di stasiun II lebih tinggi (Tabel 5).

Tabel 5. Nilai keragaman jenis makro algae di berbagai lokasi penelitian di Indonesia

\begin{tabular}{|c|l|c|c|}
\hline No & \multicolumn{1}{|c|}{ Lokasi Penelitian } & $\begin{array}{c}\text { Indeks } \\
\text { Keragaman (H') }\end{array}$ & Peneliti/Tahun \\
\hline 1. & Pulau Kai Kecil, Maluku Tenggara & 1.47 & Papalia \& Yulianto/2006 \\
\hline 2. & Ambalau, Kabupaten Buru & 2,30 & Papalia \& Yulianto/2008 \\
\hline 3. & Pulau Pengelap, Kepulauan Riau & 2,68 & A.Kadi/2010 \\
\hline
\end{tabular}

Menurut Supono dan Arbi (2010), tinggi rendahnya nilai keragaman jenis dapat disebabkan oleh berbagai faktor, antara lain jumlah jenis atau individu, substrat dan kondisi tiga ekosistem penting di daerah pesisir (padang lamun, terumbu karang dan hutan mangrove). Ekosistem padang lamun merupakan salah satu ekosistem di laut dangkal yang paling produktif. Disamping itu, ekosistem lamun mempunyai peranan penting dalam menunjang kehidupan dan perkembangan jasad hidup di laut dangkal, karena ekosistem lamun menyediakan tempat tinggal serta makanan bagi biota-biota yang ada di laut termasuk makro algae. Nilai dominansi makro algae di stasiun I sebesar 0,3, stasion II sebesar 0,1, dan stasiun III sebesar 0,2 (Tabel 4). Menurut indeks dominansi Simpson, jika indeks dominansi sama dengan nol maka tidak ada spesies yang dominan.

Hasil penelitian ini menunjukan bahwa tidak terdapat dominansi jenis tertentu pada ketiga stasiun penelitian di perairan Desa Jikumerasa, Kabupaten Buru walaupun terdapat jenis tertentu yang hadir dalam jumlah yang banyak.

Menurut Wirakusuma (2003), nilai keragaman berbanding terbalik dengan nilai dominansi. Jika nilai keragaman jenis tinggi maka nilai dominansi akan lebih rendah, dan jika nilai keragaman jenis rendah maka nilai dominansi akan lebih tinggi. Jumlah banyaknya jenis pada suatu daerah menunjukan keragaman yang tinggi sehingga cenderung tidak ada jenis tertentu yang dominan. Menurut Nybakken (1988), faktor fisik, kimia dan biologi lingkungan sangat mempengaruhi tingkat dominansi suatu jenis di lingkungan perairan.

\subsection{Parameter Fisik Kimia}

Hasil pengukuran parameter fisik kimia di perairan Desa Jikumerasa, Kabupaten Buru tahun 2013 (Tabel 6).

Tabel 6. Hasil pengukuran parameter fisik kimia di perairan Desa Jikumerasa, Kabupaten Buru tahun 2013.

\begin{tabular}{|l|c|c|c|}
\hline \multirow{2}{*}{ Parameter } & \multicolumn{3}{|c|}{ Stasiun Penelitian } \\
\cline { 2 - 4 } & Stasiun I & Stasiun II & Stasiun III \\
\hline Suhu $\left({ }^{0} \mathrm{C}\right)$ & $25,5-26,5$ & $27,5-26,6$ & $27,5-28,0$ \\
\hline
\end{tabular}




\begin{tabular}{|l|c|c|c|}
\hline Salinitas $(\%)$ & $24,8-25,0$ & $36,0-37,5$ & $36,0-35,5$ \\
\hline $\mathrm{pH}$ & 5,5 & 7,0 & 6,0 \\
\hline
\end{tabular}

Hasil pengukuran suhu di ketiga stasion penelitian berkisar antara 25,50-28,6 (Tabel 6). Kisaran suhu tersebut sesuai dengan kisaran suhu normal untuk jenis makro algae yang hidup didaerah tropis yaitu antara $15^{\circ}$ $30^{0}$ C (Luning, 1990).

Salinitas juga berpengaruh terhadap penyebaran jenis makro algae. Jenis makro algae hidup pada kisaran 28$34 \%$, tetapi kisaran optimum untuk jenis makro algae adalah 32\% (Ambas, 2006). Dari hasil penelitian yang dilakukan, salinitas di stasiun penelitian I dan stasiun penelitian II berkisar antara 36,0-37,5\% (Tabel 6). Kedua stasiun penelitian ini mempunyai salinitas yang tinggi untuk penyebaran jenis makro algae, dikarenakan kedua stasiun penelitian ini berhadapan dengan laut lepas(Laut Buru). Stasiun penelitian I mempunyai salinitas yang rendah, dikarenakan stasion penelitian ini berhadapan langsung dengan daratan, dimana adanya masukan air tawar dari sungai sekitar.

Derajat keasaman $(\mathrm{pH})$ juga berpengaruh terhadap penyebaran jenis makro algae. Jenis makro algae hidup pada kisaran pH netral 7,0 (Sadhori, 1991). Dari hasil penelitian yang dilakukan, pH di stasiun penelitian II yaitu 7,0 sehingga sangat cocok untuk penyebaran jenis makro algae. Stasiun I dan III mempunyai pH yang rendah yaitu 5,5, dan 6,0 dikarenakan pencemaran air oleh limbah domestik masyarakat sekitar.

\section{Kesimpulan}

Berdasarkan hasil penelitian terdapat 25 jenis makro algae di perairan Desa Jikumerasa Kabupaten Buru, Jenis makro algae yang mempunyai nilai kepadatan dan frekuensi kehadiran tertinggi adalah jenis Codium decorticatum yaitu sebesar $10,667 \mathrm{ind} / \mathrm{m}^{2}$ dan 0,767, Nilai indeks keragaman jenis makro algae tergolong rendah dan sedang. Nilai indeks dominansi sama dengan nol, yang menunjukan bahwa tidak ada dominansi spesies.

\section{Daftar Pustaka}

Anonima ${ }^{\text {a }}$ 2005. http://selengkapnya5.blogspot.com/2005/03/rumputlaut-perlu-dilindungi.html diakses tanggal 20 Maret 2013 Pukul 16.09 WIT.

Anonim. 2008. Kabupaten Buru. www.burupro.go.id.

Anonim ${ }^{c}$. 2008. Artikel Seaweed.www.rumputlaut.org.

Ambas. 2006. Potensi Pemanfaatan dan Prospek Pengembangan Budidaya Rumput Laut di Indonesia. Badan Pengembangan Ekspor Nasional. Dep. Perdagangan dan Koperasi. Jakarta 13 hal.

Atmadja, W.S. 1996. Pengenalan Jenis Algae Coklat. Dalam Pengenalam Jenis-Jenis Rumput Laut. Puslitbang Oseanologi LIPI-Jakarta.

Atmadja, W.S. 2007. Apa rumput laut itu sebenarnya. http://www.coreamap.or.id/print/artidde..php? Id=246. Jakarta. Sabtu 7 Juni 2008.

Bell, P.R \& A.R. Hemsley. 2004. Green Plants: Their Origin and Diversity. $2^{\text {nd }}$ ed. Cambridge University Press. Cambridge.

Bold, H.C. dan M.J. Wynne. 1978. Introduction to the alsae : Structure and reproduction . Prentice Hallof India. New Delhi.

Codero, P. A. J. 1980. Taxonomy and distribution of Philiphine useful seaweed.National Research Council of the Philipines. BictunTagig Metro Manila Philipines : 73 pp.

Dawes, C.J. 2006. Marine Algae. University of Miami Press Coral Gables Florida.

Dewi. 2006. Penyebaran Rumput Laut di Perairan Indonesia. Lembaga Oseanologi Nasional LIPI Jakarta.

Fortes, E.S. 1981. Introduction of The Seaweeds Their Characteristic and Economic Importance, Report on The Training of Glacilaria Algae. Philiphines 3-8p.

Indriani, S. 1997. Budidaya Runput Laut di Indonesia. Simposium Modernisasi Perikanan Rakyat. Jakarta.

Junaidi, W. 2004. Rumput Laut. Jenis dan Morfologinya. Departemen Pendidikan Nasional.

Ludwig, A. J. and Reynold. 1988. Statistical Ecology. A Willey-Interscience Publication. New York.

Luning. 1990. Seaweeds and Their Uses. Third Edition. New York. London

Mudjono, M. 1991. Perlindungan Ekosistem Pesisir. Departemen Pendidikan Nasional.

Nybbaken, J.W. 1988. Biologi Laut Suatu Pendekatan Ekologis. PT. Gramedia. Jakarta. 
Papalia, S. dan Yulianto, K. 2008. Penelitian Inventarisasi sumberdaya Laut di perairan Pulau Ambalau, Kabupaten Buru Selatan. UPT Balai Konservasi Biota Laut Ambon, Pusat Penelitian OseanografiLIPI. Laporan Penelitian. 12 hal.

Peraturan Daerah Kabupaten Buru Nomor 17. 2008. Pembangunan Kawasan Wisata Di Desa Jikumerasa Kabupaten Buru.

Rais, H. 2008. Budidaya Rumput Laut dan Kemungkinan Pengembangannya di Provinsi Maluku. WBL/85/WP31.

Romimohtarto, K. 2001. Ilmu Pengetahuan Tentang Biologi Laut. Srijuana. Jakarta.

Sadhori, N. 1991. Budidaya Rumput Laut. Balai Pustaka. Jakarta.

Smith, J. 1955. Their Origin Phaeophyta. Cambridge University Press. Cambridge.

Soegianto, A. 1994. Ekologi Kuantitatif. Metode Analisis Populasi dan Komunitas. Penerbit Usaha Nasional. Surabaya-Indonesia.

Soegiarto, A. 1978. Rumput Laut. Manfaat dan Potensi Usaha Budidaya. LON-LIPI. Jakarta.

Sumadiharga, S. 1997. Pengenalan Jenis-Jenis Rumput Laut Indonesia. Puslitbang Oseanologi LIPI Jakarta.

Thana, D. H. M. N. dan L. S Tandipayuk. 1993. Study on Production Quality of Seaweed Culture Eucheuma sp Using Seed. Stimulated by phythormon Auxin an gibbelrin TORANI . 3 (3); $63-67$.

Webber dan Thurman. 1985. Sub phyllum Algae. Edition Inc.

Winarno, J.W. 1990. Teknologi Pengolaan Rumput Laut. Sinar Harapan. Jakarta. 